\title{
The effect of body mass index on global brain volume in middle-aged adults: a cross sectional study Michael A Ward ${ }^{1,2}$, Cynthia M Carlsson1,2, Mehul A Trivedi1,2, Mark A Sager ${ }^{2}$ and Sterling C Johnson*1,2
}

\author{
Address: ${ }^{1}$ Geriatric Research Education and Clinical Center, Wm. S. Middleton VA Hospital, Madison, WI, USA and ${ }^{2}$ Geriatrics and Adult \\ Development, University of Wisconsin Medical School, Madison, WI, USA \\ Email: Michael A Ward - maw@medicine.wisc.edu; Cynthia M Carlsson - cmc@medicine.wisc.edu; Mehul A Trivedi - mt2@medicine.wisc.edu; \\ Mark A Sager - masager@facstaff.wisc.edu; Sterling C Johnson* - scj@medicine.wisc.edu \\ * Corresponding author
}

Published: 02 December 2005

BMC Neurology 2005, 5:23 doi:10.1 I 86/147|-2377-5-23

This article is available from: http://www.biomedcentral.com/I47/-2377/5/23

(C) 2005 Ward et al; licensee BioMed Central Ltd.

This is an Open Access article distributed under the terms of the Creative Commons Attribution License (http://creativecommons.org/licenses/by/2.0), which permits unrestricted use, distribution, and reproduction in any medium, provided the original work is properly cited.
Received: 04 April 2005

Accepted: 02 December 2005

\begin{abstract}
Background: Obesity causes or exacerbates a host of medical conditions, including cardiovascular, pulmonary, and endocrine diseases. Recently obesity in elderly women was associated with greater risk of dementia, white matter ischemic changes, and greater brain atrophy. The purpose of this study was to determine whether body type affects global brain volume, a marker of atrophy, in middle-aged men and women.
\end{abstract}

Methods: TI-weighted 3D volumetric magnetic resonance imaging was used to assess global brain volume for II4 individuals 40 to 66 years of age (average $=54.2$ years; standard deviation $=6.6$ years; 43 men and 7I women). Total cerebrospinal fluid and brain volumes were obtained with an automated tissue segmentation algorithm. A regression model was used to determine the effect of age, body mass index (BMI), and other cardiovascular risk factors on brain volume and cognition.

Results: Age and BMI were each associated with decreased brain volume. BMI did not predict cognition in this sample; however elevated diastolic blood pressure was associated with poorer episodic learning performance.

Conclusion: These findings suggest that middle-aged obese adults may already be experiencing differentially greater brain atrophy, and may potentially be at greater risk for future cognitive decline.

\section{Background}

The prevalence of overweight and obese people in the United States and other developed nations has progressively increased over the last twenty years and is now at epidemic proportions[1]. It is estimated that greater than $60 \%$ of all Americans are overweight, and approximately one-half of that group are classified as obese[2]. Previous studies have found that obesity reduces life expectancy [3] by causing or exacerbating various medical conditions including coronary heart disease (CHD), type 2 diabetes mellitus, hypertension, obstructive sleep apnea, and stroke[4]. Neurocognitive health may also be related to obesity. A recent study determined that obesity was strongly associated with poorer cognitive function in individuals over 65 years of age [5]. In a population-based sample of women aged 70-89 years, greater body mass 
index (BMI) in middle and later life was associated with cerebral white matter ischemic change [6], a higher incidence of dementia, particularly Alzheimer's disease (AD) [7], and temporal lobe atrophy [8] in later life.

Brain atrophy involves the loss of tissue volume and is commonly seen with increasing age [9-11] and neurodegenerative disease[12]. Vascular factors intrinsic to overweight individuals, such as hypertension[13,14], hypercholesterolemia $[13,15]$, endothelial dysfunction[16,17], and diabetes [18-20] have all been linked to greater risk for dementia or brain atrophy in the elderly. Furthermore, older adults with better cardiovascular fitness demonstrate significant improvements in cognitive function and a significant slowing of age-related atrophy of gray and white matter[21]. Together these findings suggest that older overweight individuals have a higher risk of accelerated brain atrophy and concomitant cognitive decline.

While the deleterious effects of obesity on the brain in the geriatric population are now apparent, it is not known whether this relationship occurs in younger persons or is unique to older populations. This is an important question because interventions to reduce the adverse effects of obesity may have a larger public health impact when implemented at younger ages. The purpose of the present study was to determine whether the effect of BMI on brain atrophy previously observed in elderly females [8] might also be observable in cognitively healthy adults between the ages of 40 and 66, and to determine the relationships between this effect and associated cardiovascular factors (hypertension and hypercholesterolemia).

\section{Methods}

One hundred seventeen participants (44 male, 73 female) with a mean age of 54.2 years $(S D=6.5)$ were studied with magnetic resonance imaging (MRI) and cognitive testing as part of a cross-sectional study analyzing factors related to global brain volume and cognition. Sixty-five participants were recruited from an existing registry known as the Wisconsin Registry for Alzheimers' Prevention (WRAP)[22] consisting of cognitively normal middle-aged adults who had at least one parent with $\mathrm{AD}$. These participants were recruited to enrich the sample with individuals having risk factors for $\mathrm{AD}$. The remaining fifty-two participants were recruited somewhat simultaneously from the University of Wisconsin-Madison (UWM) community. This convenience sample was selected to have no known first-degree family history of $\mathrm{AD}$ (with parents surviving until at least age 70 without dementia). All participants in this study were required to be between the ages of 40 and 66 and have no current major Axis I psychiatric disease or history of major medical conditions (i.e., traumatic brain injury, neurovascular infarctions, brain neoplasms or ischemic changes, history of cancer, diabetes, or condition requiring an invasive brain procedure). Additionally, participants were required to have normal cognitive function, and MRI scanner compatibility. Lastly, participants on any medication with potential to affect cerebral perfusion or cognition (such as beta blockers, calcium channel antagonists, Angiotensin-converting Enzyme (ACE) inhibitors, statins, or Selective Serotonin Reuptake Inhibitors (SSRIs)) were excluded from the analysis.

All participants completed a detailed health history questionnaire, and were administered a battery of neuropsychological tests and laboratory blood tests. Data were collected on Apolipoprotein E (APOE) genotype, nonfasting total blood cholesterol level, blood pressure (BP), height and weight (for BMI calculation). BP was measured with the subject seated and at rest using an automated BP machine. Body height and weight were collected to the nearest 0.5 -inch and one pound respectively. The battery of neuropsychological tests [23] included the following: portions of the Wechsler Adult Intelligence Scale-Third Edition (WAIS-III), the Rey Auditory Verbal Learning Test (RAVLT), Trail Making Test A and B, and the Center for Epidemiological Studies Depression (CES-D) Inventory. All participants gave written informed consent under a protocol approved by the local institutional review board. This study was performed in a manner that was in accordance with the Declaration of Helsinki.

\section{Brain imaging}

MRI was performed using a General Electric 3.0 Tesla SIGNA (Waukesha, WI) MRI system. A 3D IR-prepped fast gradient echo pulse sequence provided high-resolution T1-weighted structural images. The whole brain was imaged in the axial plane with the following parameters: inversion time $=600 \mathrm{~ms}$, fast gradient echo read-out with $\mathrm{TR} / \mathrm{TE} /$ flip $=9 \mathrm{~ms} / 1.8 \mathrm{~ms} / 20^{\circ} ;$ acquisition matrix $=256 \times$ $192 \times 124$ (interpolated to $256 \times 256 \times 124$ ); field of view $=240 \mathrm{~mm}$; slice thickness $=1.2 \mathrm{~mm}$ (124 slices) $; \pm 16 \mathrm{kHz}$ receiver bandwidth.

A Fast Recovery Fast Spin Echo 2D T2-weighted axial sequence was also acquired with the same start and stop locations as the $\mathrm{T} 1$ weighted images. The parameters were: field of view $=240 \mathrm{~mm}$, matrix $256 \times 256 \times 64, \mathrm{TR}=9000$ $\mathrm{ms}, \mathrm{TE}=93 \mathrm{~ms}$, flip angle $=90$. Seventy slices were acquired; slice thickness $=1.7 \mathrm{~mm}$ with $0.3 \mathrm{~mm}$ skip. An experienced neuroradiologist examined all images for evidence of any neurovascular disease or structural abnormality that would exclude the subject from the analysis (see exclusions above). 
Table I: Demographic and cognitive measures for men and women

\begin{tabular}{ll}
\hline Demographic and Cognitive Variables & Mean (SD) \\
\hline Age (years) & $54.2(6.6)$ \\
Education (years) & $16.4(2.5)$ \\
Classification: $\mathrm{n}=$ Normal / Overweight / Obese $^{\mathrm{a}}$ & $5 \mathrm{I} / 42 / 2 \mathrm{I}$ \\
Trail Making Test B (seconds) $^{\mathrm{b}}$ & $61.3(20.2)$ \\
WAIS-III-Digit Span raw score $^{\mathrm{b}}$ & $17.9(3.8)$ \\
RAVLT-Total raw score $^{\mathrm{b}}$ & $49.6(7.9)$ \\
CES-D $^{\mathrm{b}}$ & $4.6(5.2)$ \\
\hline
\end{tabular}

Data are presented as mean (standard deviation).

Notes: aNormal, overweight, and obese body types are defined using the World Health Organization's classification system.

bThe cognitive and mood variables are presented for the 108 participants in the cognitive analysis. Demographic variables are for the full sample of II4.

\section{Global brain atrophy determination}

Global brain volumes, calculated from T1-weighted images, were analyzed using the cross sectional method of Structural Image Evaluation, using Normalization, of Atrophy (SIENAX) within the FSL 3.1 $\beta$ software suite[24]. The SIENAX parameters were set for a three-class segmentation of tissue type and at a 0.3 threshold for segmenting the brain from extra-axial soft tissue. SIENAX analysis yielded whole-brain volumetric data, in units of cubic millimeters, for three different tissue types: cerebral spinal fluid (CSF), gray matter, and white matter. Total intracranial volume (TICV) was defined as the sum of the three tissue types, and whole brain parenchyma volume (BV) was defined as the sum of gray matter and white matter. BV was divided by TICV to obtain a normalized brain volume (NBV) with respect to head size.

\section{BMI classification}

BMI values were calculated in standard fashion by dividing the weight in kilograms by the square of height in meters. BMI groups were defined using the World Health Organization's (WHO) classification system: Underweight, less than 18.5; Normal, 18.5-24.9; Overweight, 25.0-29.9; and Obese, greater than 30.0 (in units $\mathrm{kg} / \mathrm{m}^{2}$ ) [25]. There were not enough underweight participants in this study group to analyze the effects of underweight on global brain atrophy. Therefore, individuals classified as underweight were not included in the statistical analysis.

\section{Statistical analysis}

First, Student's t-tests were performed to determine whether the participants differed by family history of $\mathrm{AD}$ status/referral source. These analyses revealed that UWM participants were more highly educated than the WRAP participants, mean $=16.9(\mathrm{SD}=2.4)$ and mean $=15.9(\mathrm{SD}$ $=2.5$ ) respectively $(\mathrm{t}[112]=-2.10 ; \mathrm{p}=0.038)$. In addition, the frequency of the APOE $\varepsilon 4$ allele was more prevalent in WRAP participants $(54.0 \%)$ compared to the UWM par- ticipants $(13.7 \%)$ (chi-square $[1]=23.5 ; \mathrm{p}<0.001)$. No other variables were found to be significantly different between the two groups. Nevertheless, $1^{\text {st }}$ degree family history of AD was treated as an independent variable in the ensuing stepwise regression model.

Next, linear regression analyses and stepwise regression analyses were used to predict the effect of BMI, age, nonfasting total blood cholesterol level, systolic and diastolic $\mathrm{BP}$, family history of $\mathrm{AD}$, gender, education, and genotype on the dependent variables of NBV and cognition in separate analyses. Family history of AD, gender, and APOE genotype were entered into the model as dichotomous variables: history/no history of $\mathrm{AD}$, male/female, and presence/absence of the $\varepsilon 4$ allele, respectively. A method advocated by Baron et al. [26] was used to determine whether any variable within the stepwise linear regression model mediated the effect of BMI on NBV.

Three participants were not included in the brain volume analysis. Two participants were classified as underweight and one participant was discovered to have a previously undiagnosed brain tumor. Therefore the final sample size equaled 114 participants. Nine participants were not included in the cognition analysis; five participants scored a fifteen or higher on the CES-D inventory suggesting symptoms of depression, one participant did not complete the CES-D inventory, and the remaining three participants were the same participants excluded in the brain atrophy analysis ( $n=108$ participants). Therefore the final sample size for the cognition analysis equaled 108 participants.

\section{Results}

One hundred fourteen middle-aged (mean age 54) adults were administered a comprehensive battery of neuropsychological tests and structural MRI scans in this cross-sectional study examining the brain and cognitive effects associated with various AD risk factors. Baseline demographics, cognitive measures, and predictor variables are shown in Tables 1 and 2 .

An initial linear regression analysis examined the effect of age and BMI on NBV to determine whether the effect observed in elderly females [8] could be observed in younger men and women. This analysis indicated that both age $(\beta=-0.390 ; \mathrm{t}=-4.614 ; \mathrm{p}<0.0001)$ and $\mathrm{BMI}(\beta=$ $-0.220 ; \mathrm{t}=-2.605 ; \mathrm{p}=0.010)$ were significant predictors of $\operatorname{NBV}\left(R^{2}=0.206 ; \mathrm{F}[111,2]=14.432 ; \mathrm{p}<0.00001\right)$. Figure 1 shows that elevated BMI is associated with decreased NBV (after adjusting for age). To determine whether additional variables may also predict NBV, a stepwise linear regression analysis was used to examine the effects of age, $\mathrm{BMI}$, family history of AD, APOE genotype, total cholesterol, systolic and diastolic BP, and gender on NBV. This 
Table 2: Independent associations between each predictor variable and age-adjusted NBV

\begin{tabular}{lllll}
\hline Regressor & Mean (SD) & Range & $\beta$-value & P-value \\
\hline BMI $\left(\mathrm{kg} / \mathrm{m}^{2}\right)$ & $26.0(4.4)$ & $(19.0-39.7)$ & -0.22 & 0.010 \\
Total Cholesterol (mg/dL) & $208.0(37.8)$ & $(114-339)$ & -0.12 & 0.178 \\
Systolic BP (mm Hg) & $132.4(17.2)$ & $(102-205)$ & -0.15 & 0.092 \\
Diastolic BP (mm Hg) & $79.4(10.4)$ & $(54-110)$ & -0.09 & 0.328 \\
Family History AD (y/n) & $63 / 51$ & & 0.07 & 0.448 \\
APOE Genotype (E4/no $\varepsilon 4)$ & $41 / 73$ & & -0.04 & 0.660 \\
Gender (Male/Female) & $43 / 71$ & 0.13 & 0.137
\end{tabular}

$\mathrm{n}=$ II4. $\beta$-values, acquired using individual linear regression analyses with each of the above predictors entered after age, reflect age-adjusted predictions of NBV.

analysis found that age $(\beta=-0.389 ; \mathrm{t}=-4.337 ; \mathrm{p}<0.001)$ and BMI $(\beta=-0.224 ; \mathrm{t}=-2.495 ; \mathrm{p}<0.014)$ together were the best predictors of NBV $\left(R^{2}=0.205 ; \mathrm{F}[99,2]=12.756\right.$; $\mathrm{p}<0.0001)$. No other variables were significant.

Pearson correlations determined that BMI was significantly associated with cholesterol $(r=0.21, \mathrm{p}<0.04)$ and systolic BP $(r=0.36, \mathrm{p}<0.001)$ but was not associated with any other predictor variable. Neither cholesterol nor systolic BP were significantly associated with NBV (results are summarized in Table 2), and therefore did not appear to mediate the effect of BMI on NBV according to criteria specified by Baron et al. [26].

Next we applied the same stepwise model above, including education to predict the non-crystallized cognitive abilities of learning, processing speed and working memory in separate regression models. Age $(\beta=-0.315 ; \mathrm{t}=-$ 3.417; $\mathrm{p}<0.001)$ and diastolic $\mathrm{BP}(\beta=-0.233 ; \mathrm{t}=-2.526$; $\mathrm{p}=0.013)$ were significant predictors of learning $\left(R^{2}=\right.$ $0.157 ; \mathrm{F}[101,2]=9.252 ; \mathrm{p}<0.001)$. Age was the only significant predictor of processing speed $\left(R^{2}=0.081 ; \mathrm{F}[100\right.$, $1]=8.454 ; \mathrm{p}<0.01)$. There was no significant predictor of working memory in this sample. Average neuropsychological scores are given in Table 1.

\section{Discussion}

This study found that elevated BMI is associated with reduced brain volumes, suggesting greater global brain atrophy in middle-aged adults even after adjusting for age. Episodic learning, working memory, and processing speed abilities were not associated with BMI in this sample indicating that the possible effect on cerebral atrophy had not influenced cognition in participants with a high BMI. Episodic learning was related to diastolic BP, which indicates that certain cardiovascular risk factors may be associated with cognition. However, this finding was isolated to only one of our three categories of cognition. Longitudinal studies are needed to assess future cognitive consequences associated with cardiovascular risk factors.
Our finding that BMI affects brain volume at a relatively young age extends prior research on the harmful effects of obesity on the brain. We found a $2.4 \%$ difference in brain parenchyma volume for participants classified by the WHO as obese $\left(n=21\right.$ people; average $\left.B M I=33.3 \mathrm{~kg} / \mathrm{m}^{2}\right)$ compared to participants at a normal, healthy weight $(\mathrm{n}=$ 51 people; average $B M I=22.6 \mathrm{~kg} / \mathrm{m}^{2}$ ). Although the magnitude of this difference is not large in this cross-sectional sample, when we consider these results in the context of the younger age of our sample ( 54.2 years), it follows that obesity in middle age may render an individual more vulnerable to brain atrophy over subsequent years, and thus more vulnerable to cognitive decline or dementia. The results of this study are consistent with others showing that life choices (i.e., proper diet, physical activity) may be neuroprotective and, therefore, potentially reduce the rate of brain atrophy and concomitant cognitive decline $[27,28]$. A longitudinal study of obese people at middle age is needed to test these hypotheses.

It is unclear through what mechanisms obesity affects brain volume. Central obesity is associated with risk factors composing the metabolic syndrome, including high triglyceride levels, low HDL cholesterol levels, hypertension, insulin resistance, and prothrombotic and proinflammatory states. Prior studies indicate that some of these risk factors such as mid-life elevations in blood pressure, total cholesterol, and inflammatory markers, are risk factors for late-life dementia[13,29-31]. In the present study, neither BP nor non-fasting total cholesterol was associated with current NBV (though systolic BP did show a trend). These vascular risk factors may affect chronic cerebral perfusion and $\beta$-amyloid generation, thus influencing neuronal degeneration. Leptin, a peptide related to obesity, also affects $\beta$-amyloid regulation [32]. Further studies are needed to determine the mechanism by which BMI affects brain atrophy in middle-aged adults, and whether this may have future deleterious consequences on brain structure or function.

Brain tissue is strongly dependent upon oxygen for survival and is thus vulnerable to hypoxic and ischemic con- 


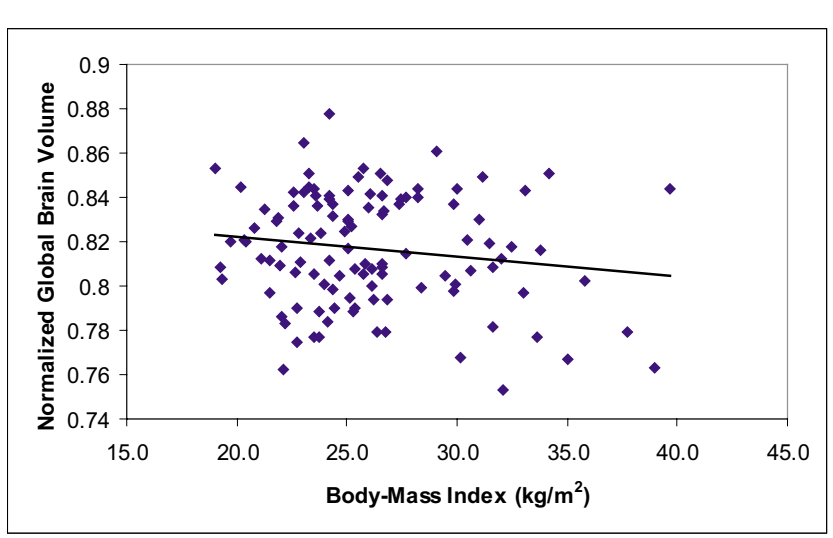

Figure I

NBV versus BMI. Age adjusted values of NBV plotted versus $\mathrm{BMI}$ scores. NBV is shown to decrease proportionally with increasing BMI $(r=-0.232, \mathrm{p}<0.03)$.

ditions. Hypoxia is an inherent consequence of many of the conditions caused or exacerbated by obesity. Obstructive sleep apnea[4], CHD [33], asthma [34], and low cardiovascular fitness[21] may lead to hypoxia which, in chronic situations, may lead to cognitive decline and neuronal death[35]. Hypoxia is often a consequence of hypoperfusion, which is strongly associated with endothelial dysfunction common to individuals with hypertension, atherosclerosis, and CHD. Endothelial dysfunction, as a result of oxidative stress, may induce neuronal damage and initiate neurodegenerative change[17].

Prevention or postponement of the onset of dementia has the potential to drastically impact the prevalence of dementia. The prevalence of $\mathrm{AD}$ in the United States alone is projected to quadruple in the next 50 years, and if disease onset could be delayed by only one year, it would result in 800,000 fewer cases[36]. It has been shown that a person's weight is a reflection of their habitual physical activity[4]. Given the rapid increase in obesity in the United States, targeting weight management may significantly impact the prevalence of dementia. High dietary fat intake has been shown to increase the risk of dementia [37]. Physical fitness significantly improves cognitive function in older adults[21] and exercise increases the production of brain-derived neurotrophic factor (BDNF) and insulin-like growth factor I (IGF-I). BDNF and IGF-I are neurotrophic hormones that are important for neurogenesis, which may protect against neurodegeneration seen with aging[38]. In older adults the rate of change in brain volume may be diminished in persons with better cardiovascular fitness[39].

There were some limitations of this study. First, the range of BMI was truncated because of the small-bore radius (55 $\mathrm{cm}$ ) inherent to the MRI scanner. Therefore, participants in this study could not exceed 260 pounds, which did not permit an analysis of the effects of extreme obesity. Next, insulin-dependent diabetic participants were excluded from this study because diabetes has been shown to be a risk factor for dementia [18-20] and therefore could be an important confounder in the analysis. The incidence of diabetes in our study population was less than $1 \%$, which was not enough to determine its affect on global brain volume. Next, the design of this study was cross-sectional which only allowed for inferences between participants over a single time point. A longitudinal study is needed to clarify if the reduced brain volume associated with elevated $\mathrm{BMI}$ is representative of a progressive brain atrophy and concomitant cognitive decline. Additionally, nonfasting, instead of the more accurate fasting blood cholesterol values were used as potential predictors of NBV. Furthermore, the BMI measurement itself is only an estimate of obesity; it does not accurately distinguish fat mass from lean mass. The highest risk for adverse consequences related to overweight individuals are best indicated by excess amounts of adipose tissue, especially that within the intra-abdominal region. Waist circumference and skinfold thickness measurements in conjunction with BMI would have provided a more precise measure of the amount and location of this excess body fat. Finally, this study population was self-selected from a group of highly educated, motivated volunteers; these findings may not be representative of the general population. However, these findings are important in understanding how to potentially target preventive therapies for at-risk individuals.

\section{Conclusion}

This study found that elevated BMI is associated with lesser brain volume in middle-aged adults (mean age $=54$ years) even after adjusting for age. This study extends prior research that indicated a similar effect in a populationbased sample of females aged 70 to 84 years with elevated BMIs from middle age through later life ( 46 to 84 years). Further, longitudinal studies are needed to determine whether the effect we have observed at middle age results in greater rate of cerebral atrophy over time, and whether this effect may increase the risk of future cognitive decline and incidence of dementia.

\section{Competing interests}

The author(s) declare that they have no competing interests.

\section{Authors' contributions}

MAW carried out the statistical analysis, drafted the manuscript, and assisted in the acquisition of data. CMC contributed to study conception, participated in its design, and assisted in drafting the manuscript. MAT assisted in data acquisition, statistical analyses, interpreting the 
results, and drafting the manuscript. MAS assisted in data acquisition, interpreting the results, and writing the manuscript. SCJ drafted the manuscript, conceived of the study concept and design, assisted in the statistical analysis, and interpretation of the results. All authors read and approved the final manuscript.

\section{Acknowledgements}

This study was supported by AG02I I55. The assistance of Britta Torgerson, Taylor Schmitz, Michele Ries, Ph. D., Howard Rowley, M.D., Rebecca Koscik, Ph.D. Justin Dunker, Kristi Kalmoe, Allie Wichmann, Michael Anderle, and Ron Fisher is greatly appreciated. We especially thank the participants of this study.

\section{References}

I. Kuczmarski RJ, Flegal KM, Campbell SM, Johnson CL: Increasing prevalence of overweight among US adults. The National Health and Nutrition Examination Surveys, 1960 to 1991. Jama I994, 272(3):205-2I I.

2. Flegal KM, Carroll MD, Ogden CL, Johnson CL: Prevalence and trends in obesity among US adults, 1999-2000. Jama 2002, 288(14): 1723-1727.

3. Olshansky SJ, Passaro DJ, Hershow RC, Layden J, Carnes BA, Brody J. Hayflick L, Butler RN, Allison DB, Ludwig DS: A Potential Decline in Life Expectancy in the United States in the 2 Ist Century. The New England Journal of Medicine 2005, 352(II): II38-1145

4. Kopelman PG: Obesity as a medical problem. Nature 2000, 404(6778):635-643.

5. Jeong SK, Nam HS, Son MH, Son EJ, Cho KH: Interactive Effect of Obesity Indexes on Cognition. Dement Geriatr Cogn Disord 2004, 19(2-3):9|-96.

6. Gustafson DR, Steen B, Skoog I: Body mass index and white matter lesions in elderly women. An 18-year longitudinal study. Int Psychogeriatr 2004, 16(3):327-336.

7. Gustafson D, Rothenberg E, Blennow K, Steen B, Skoog I: An I8year follow-up of overweight and risk of Alzheimer disease. Arch Intern Med 2003, 163(13): 1524-1528.

8. Gustafson D, Lissner L, Bengtsson C, Bjorkelund C, Skoog I: A 24year follow-up of body mass index and cerebral atrophy. Neurology 2004, 63(10): |876-|88I.

9. Fotenos AF, Snyder AZ, Girton LE, Morris JC, Buckner RL: Normative estimates of cross-sectional and longitudinal brain volume decline in aging and AD. Neurology 2005, 64(6): 1032- 1039.

10. Jernigan TL, Archibald SL, Berhow MT, Sowell ER, Foster DS, Hesselink JR: Cerebral structure on MRI, Part I: Localization of age-related changes. Biol Psychiatry 199|, 29(1):55-67.

II. Blatter DD, Bigler ED, Gale SD, Johnson SC, Anderson CV, Burnett BM, Parker N, Kurth S, Horn SD: Quantitative volumetric analysis of brain MR: normative database spanning 5 decades of life. AJNR Am J Neuroradiol 1995, I6(2):24I-25I.

12. Kantarci K, Jack CRJ: Neuroimaging in Alzheimer disease: an evidence-based review. Neuroimaging Clin N Am 2003, I3(2): 197-209.

13. Kivipelto M, Helkala EL, Laakso MP, Hanninen T, Hallikainen M, Alhainen K, livonen S, Mannermaa A, Tuomilehto J, Nissinen A, Soininen H: Apolipoprotein E epsilon4 allele, elevated midlife total cholesterol level, and high midlife systolic blood pressure are independent risk factors for late-life Alzheimer disease. Ann Intern Med 2002, I37(3): 149-155.

14. Heijer T, Skoog I, Oudkerk M, de Leeuw FE, de Groot JC, Hofman A, Breteler MM: Association between blood pressure levels over time and brain atrophy in the elderly. Neurobiol Aging 2003, 24(2):307-3।3.

15. Meyer JS, Rauch GM, Crawford K, Rauch RA, Konno S, Akiyama H, Terayama $Y$, Haque A: Risk factors accelerating cerebral degenerative changes, cognitive decline and dementia. Int J Geriatr Psychiatry 1999, I4( I 2): 1050-106I.

16. Togo T, Katsuse O, Iseki E: Nitric oxide pathways in Alzheimer's disease and other neurodegenerative dementias. Neurol Res 2004, 26(5):563-566.
17. Aliev G, Obrenovich ME, Smith MA, Perry G: Hypoperfusion, Mitochondria Failure, Oxidative Stress, and Alzheimer Disease. J Biomed Biotechnol 2003, 2003(3): $162-163$.

18. Leibson CL, Rocca WA, Hanson VA, Cha R, Kokmen E, O'Brien PC Palumbo PJ: Risk of dementia among persons with diabetes mellitus: a population-based cohort study. Am J Epidemiol 1997, 145(4):30।-308.

19. Ott A, Stolk RP, van Harskamp F, Pols HA, Hofman A, Breteler MM: Diabetes mellitus and the risk of dementia: The Rotterdam Study. Neurology 1999, 53(9):1937-1942.

20. Schnaider Beeri M, Goldbourt U, Silverman JM, Noy S, Schmeidler J, Ravona-Springer R, Sverdlick A, Davidson M: Diabetes mellitus in midlife and the risk of dementia three decades later. Neurology 2004, 63( ( 0): 1 $902-1907$.

2I. Kramer AF, Bherer L, Colcombe S], Dong W, Greenough WT: Environmental influences on cognitive and brain plasticity during aging. J Gerontol A Biol Sci Med Sci 2004, 59(9):M940-57

22. Sager MA, Hermann BP, La Rue A: Middle-aged Children of Persons with Alzheimer's Disease: APOE Genotypes and Cognitive Function in the Wisconsin Registry for Alzheimer's Prevention. Journal of Geriatric Psychiatry and Neurology in press.

23. Spreen O, Strauss E: A Compendium of Neuropsychological Tests. New York, Oxford; 1998.

24. Smith SM, Zhang Y, Jenkinson M, Chen J, Matthews PM, Federico A, De Stefano N: Accurate, robust, and automated longitudinal and cross-sectional brain change analysis. Neuroimage 2002, I7(I):479-489.

25. Obesity: preventing and managing the global epidemic. Report of a WHO consultation. World Health Organ Tech Rep Ser 2000, 894:i-xii, I-253.

26. Baron RM, Kenny DA: The moderator-mediator variable distinction in social psychological research: conceptual, strategic, and statistical considerations. J Pers Soc Psychol 1986, 5 I (6): II73-II82.

27. Scarmeas N, Stern Y: Cognitive reserve: implications for diagnosis and prevention of Alzheimer's disease. Curr Neurol Neurosci $\operatorname{Rep} 2004, \mathbf{4}(5): 374-380$.

28. Whalley LJ, Deary IJ, Appleton CL, Starr JM: Cognitive reserve and the neurobiology of cognitive aging. Ageing Res Rev 2004, 3(4):369-382

29. Kivipelto $M$, Helkala EL, Laakso MP, Hanninen T, Hallikainen M, Alhainen K, Soininen H, Tuomilehto J, Nissinen A: Midlife vascular risk factors and Alzheimer's disease in later life: longitudinal, population based study. Bmj 200I, 322(7300): I447-I45I.

30. Knopman D, Boland LL, Mosley T, Howard G, Liao D, Szklo M, McGovern P, Folsom AR: Cardiovascular risk factors and cognitive decline in middle-aged adults. Neurology 200I, 56(I):42-48.

3I. Schmidt R, Schmidt H, Curb JD, Masaki K, White LR, Launer LJ: Early inflammation and dementia: a 25-year follow-up of the Honolulu-Asia Aging Study. Ann Neurol 2002, 52(2): 168-174.

32. Fewlass DC, Noboa K, Pi-Sunyer FX, Johnston JM, Yan SD, Tezapsidis $\mathrm{N}$ : Obesity-related leptin regulates Alzheimer's Abeta. Faseb | 2004, I 8(1 5): 1870-1878.

33. Bass JL, Corwin M, Gozal D, Moore C, Nishida H, Parker S, Schonwald A, Wilker RE, Stehle S, Kinane TB: The effect of chronic or intermittent hypoxia on cognition in childhood: a review of the evidence. Pediatrics 2004, I | 4(3):805-8I6.

34. Ronmark E, Andersson C, Nystrom L, Forsberg B, Jarvholm B, Lundback $B$ : Obesity increases the risk of incident asthma among adults. Eur Respir J 2005, 25(2):282-288.

35. Lezak MD: Neuropsychological assessment. 4th edition. Oxford ; New York, Oxford University Press; 2004:xiv, 1016.

36. Brookmeyer R, Gray S, Kawas C: Projections of Alzheimer's disease in the United States and the public health impact of delaying disease onset. Am J Public Health I998, 88(9): I 337-I 342.

37. Morris MC, Evans DA, Bienias JL, Tangney CC, Bennett DA, Aggarwal $\mathrm{N}$, Schneider J, Wilson RS: Dietary fats and the risk of incident Alzheimer disease. Arch Neurol 2003, 60(2):194-200.

38. Cotman CW, Berchtold NC: Exercise: a behavioral intervention to enhance brain health and plasticity. Trends Neurosci 2002, 25(6):295-30I.

39. Colcombe SJ, Erickson KI, Raz N, Webb AG, Cohen NJ, McAuley E, Kramer AF: Aerobic fitness reduces brain tissue loss in aging humans. J Gerontol A Biol Sci Med Sci 2003, 58(2): 176- 180. 


\section{Pre-publication history}

The pre-publication history for this paper can be accessed here:

http://www.biomedcentral.com/1471-2377/5/23/prepub

Publish with Bio Med Central and every scientist can read your work free of charge

"BioMed Central will be the most significant development for disseminating the results of biomedical research in our lifetime. " Sir Paul Nurse, Cancer Research UK

Your research papers will be:

- available free of charge to the entire biomedical community

- peer reviewed and published immediately upon acceptance

- cited in PubMed and archived on PubMed Central

- yours - you keep the copyright

Submit your manuscript here:

http://www.biomedcentral.com/info/publishing_adv.asp 